\title{
The interplay between daptomycin and the immune system
}

\author{
Theodoros Kelesidis* \\ Department of Medicine, Division of Infectious Diseases, David Geffen School of Medicine, University of California, Los Angeles, CA, USA
}

\author{
Edited by: \\ Mario T. Philipp, Tulane University, \\ USA \\ Reviewed by: \\ Monica E. Embers, Tulane University, \\ USA \\ Catherine A. Brissette, University of \\ North Dakota School of Medicine and \\ Health Sciences, USA \\ Carlo Riccardi, University of Perugia, \\ Italy \\ *Correspondence: \\ Theodoros Kelesidis, Department of \\ Medicine, Division of Infectious \\ Diseases, David Geffen School of \\ Medicine, University of California, \\ 37-121 Center for Health Sciences, \\ 10833 LeConte Avenue, Los Angeles, \\ CA 90095, USA \\ e-mail: tkelesidis@mednet.ucla.edu
}

Antibiotics may have bacteriostatic or bactericidal effects but may also cause immunomodulation. Lipopeptides are known immunomodulators that interact with pattern recognition receptors such as Toll-like receptors in antigen presenting cells. Daptomycin is a novel lipopeptide antibiotic with a lipid moiety and unique structure that in the presence of divalent ions may directly interact with lipid membrane phospholipids, the major component of lipid membranes in immune cells. Daptomycin may also penetrate immune cells including neutrophils and macrophages. However, the possible immunomodulatory effects of daptomycin remain unknown. Understanding these effects is important to determine whether this agent can provide protection against infectious challenge through multiple mechanisms. Preliminary studies suggest that daptomycin may have minimal effects on cytokine production and may have synergistic immunomodulatory effects in combination with other immunomodulators. This review focuses on the hypothesis that daptomycin may also have immunomodulatory effects but further studies are needed to investigate this hypothesis.

Keywords: daptomycin, immunity, lipopeptide, immunomodulation, antibiotics

\section{INTRODUCTION}

The increasing antimicrobial resistance represents a challenge in treating infections $(1,2)$. The increased incidence of multidrugresistant gram-positive pathogens such as methicillin-resistant Staphylococcus aureus (MRSA) (2) emphasizes the need for antimicrobials with different mechanisms of action (2). Daptomycin is a lipopeptide antibiotic that is bactericidal against gram-positive bacteria including MRSA (3). The Food and Drug Administration has approved daptomycin for the treatment of skin infections caused by gram-positive pathogens and for the treatment of $S$. aureus right-sided endocarditis and bacteremia (4). The exact mechanism of action of this lipopeptide antibiotic remains to be fully elucidated but its antimicrobial activity is entirely dependent on calcium. Although some antibiotics may cause immunomodulation (5-8) and lipopeptides are known immunomodulators (9-11), the possible immunomodulatory effects of daptomycin have been minimally investigated. In this review, the suggested mechanism of action and the possible immunomodulatory role of the lipopeptide antibiotic daptomycin are discussed.

\section{DAPTOMYCIN, A PROTOTYPE OF THE ACIDIC LIPOPEPTIDE FAMILY}

Daptomycin is a cyclic anionic lipopeptide antibiotic that was isolated from cultures of Streptomyces roseosporus $(3,12)$. This lipopeptide consists of 13 amino acid residues, which include 3 exocyclic D-amino acid residues (D-asparagine, D-alanine, and D-serine) and 3 non-proteinogenic amino acids including kynurenine (Kyn) that forms the macrolactone ring through an ester bond with Thr (13). N-decanoyl fatty acid chain, consisting of 10-13 carbon atoms, attached to the $\mathrm{N}$-terminal Trp- 1 is also characteristic $(14,15)$ (Figure 1). Thus, daptomycin has a lipophilic tail and a water-soluble core consisting of 13 amino acids. Daptomycin inherits a specific motif (DXDG), which is proposed to be involved in $\mathrm{Ca}^{2+}$ binding (16). Several other calcium-dependent lipopeptide antibiotics are known, including calcium-dependent antibiotic (CDA) (17-19) and they also share a long chain fatty acid attached to the cyclic core. The mechanistic and structural aspects of non-ribosomal product assembly of this lipopeptide have been previously reviewed in detail $(20,21)$.

\section{MECHANISM OF ACTION OF DAPTOMYCIN THE MECHANISM OF ACTION OF DAPTOMYCIN REMAINS UNCLEAR BUT IS HIGHLY DEPENDENT ON DIVALENT IONS}

Daptomycin acts bactericidal in a concentration-dependent manner but the mechanism of action of daptomycin is still under investigation (22). Daptomycin has a unique mode of antimicrobial action since free calcium ions at a concentration of $50 \mathrm{mg} / \mathrm{l}$ are required for the drug to become active and to bind to the bacterial cytoplasmic membrane (23). Currently, mechanistic studies largely focus on membrane insertion models and structures of daptomycin in the presence and absence of $\mathrm{Ca}^{2+}$ and it has been suggested that divalent cations promote formation of micelle by interacting with the negatively charged components of bacterial cell membranes such as phospholipids $(14,24)$ (Figure 1).

\section{DIVALENT IONS INDUCE CONFORMATIONAL CHANGES IN DAPTOMYCIN THAT FACILITATE INTERACTION OF DAPTOMYCIN WITH THE CYTOPLASMIC MEMBRANE BILAYER}

Jung et al. (25) proposed a two-step mechanism of action of daptomycin that may explain how this lipopeptide interacts with cytoplasmic membranes. Initially in the presence of $\mathrm{Ca}^{2+}$, daptomycin binds to 1,2-dihexanoyl-sn-glycero-3-phosphocholine and experiences a minor conformational rearrangement $(14,26)$. This process increases amphipathicity of daptomycin, decreases its 


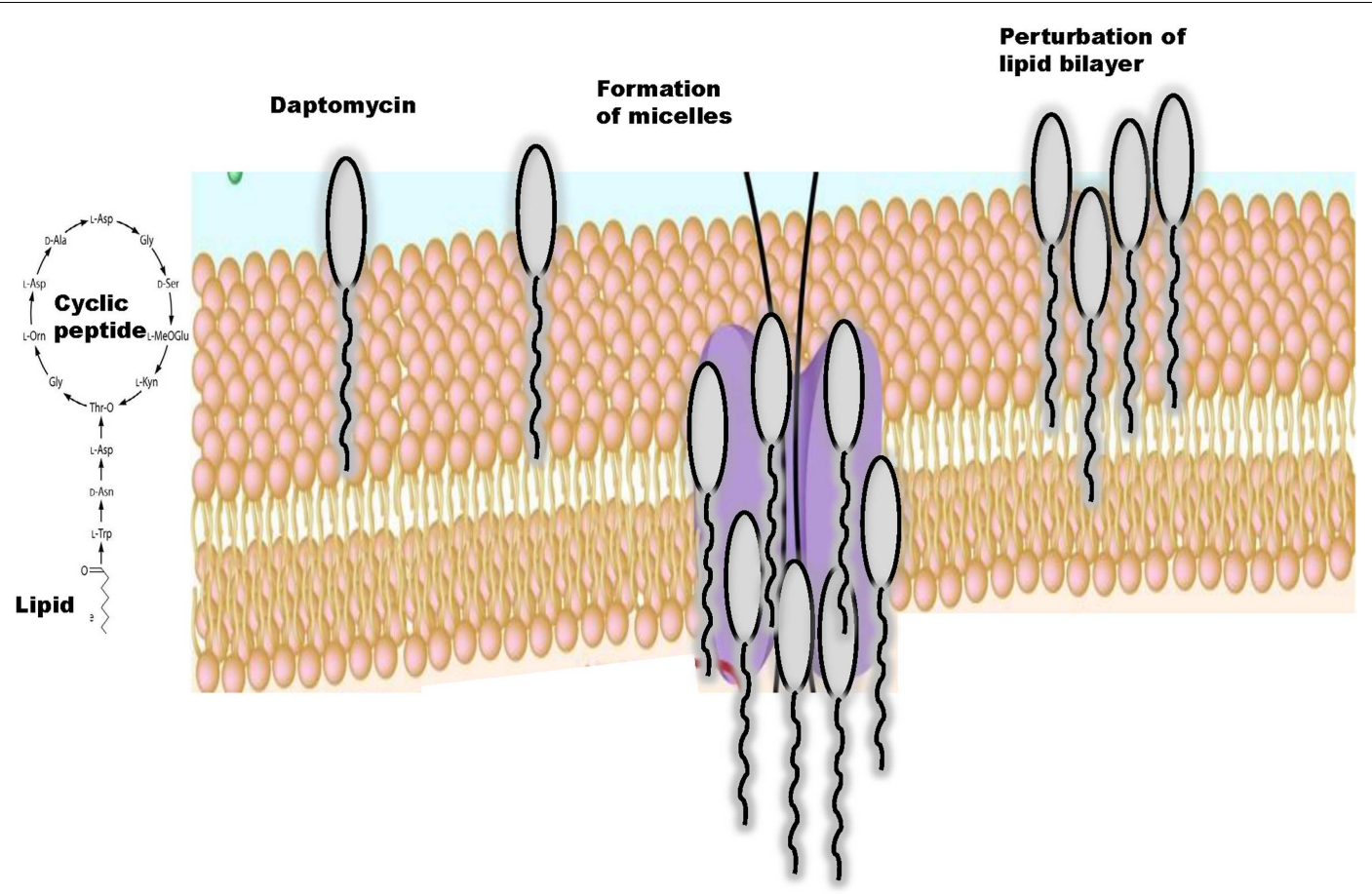

FIGURE 1 | Structure of daptomycin, a cyclic lipopeptide and interactions with the lipid bilayer.

charge, allows daptomycin to interact with neutral or acidic membranes, and facilitates oligomerization (25) and micelle formation. In a second step, daptomycin interacts with the acidic phospholipids in the presence of $\mathrm{Ca}^{2+}$ and a major conformational change allows daptomycin to insert into bilayer membranes with acidic character $(27,28)$. In this model, the lipid tail promotes the formation of micelles, which are vehicles to allow daptomycin to insert into the bilayer (27), depolarize the membrane leading to cell death $(14,22,25)$ (Figure 1). Thus, similarly to cationic peptides, the mechanism of action of daptomycin may involve multiple targets (29).

\section{DAPTOMYCIN DIRECTLY INTERACTS WITH PHOSPHOLIPIDS, A COMPONENT OF LIPID MEMBRANES}

Daptomycin can insert into artificial lipid vesicles and the membrane of gram-positive bacteria $(22,25,30)$. Daptomycin contains two aromatic lipophilic residues (Trp-1 and Kyn-13) (30, 31) that upon their insertion in the phospholipid membrane becomes less polar $(22,25,30)$. Daptomycin directly interacts with cytoplasmic membranes without requiring any receptors $(22,25,30)$ and can insert into membrane vesicles composed of phosphatidylcholine (PC) and phosphatidylglycerol (PG) (25, 30). It has also been shown that daptomycin directly interacts with pulmonary surfactant, which sequesters and inhibits the antibiotic. Surfactant is composed mainly of dipalmitoylphosphatidylcholine and PG and only low levels of cholesterol and sphingolipids contrary to most eukaryotic membranes (32). Surfactant is also $\sim 10 \%$ negatively charged PG, a major component of the gram-positive plasma membrane (33), which significantly enhances insertion of surfactant into the membrane (25). The major conformational change of daptomycin that leads to an increased perturbation of the cytoplasmic membrane is dependent on interaction with the bacterial acidic phospholipid, phosphatidyl glycerol (34). Although binding of daptomycin to bilayers containing acidic lipids primarily involves electrostatic interactions, presumably through the $\mathrm{Ca}^{2+}$-induced electrostatic bridging of the acidic amino acids in daptomycin with the acidic phospholipid head groups, the binding of daptomycin to neutral bilayers may occur through a combination of electrostatic and hydrophobic interactions $(25,35)$.

\section{LIPOPEPTIDES LIKE DAPTOMYCIN MAY DIRECTLY INTERACT WITH THE LIPID MEMBRANES OF IMIMUNE CELLS BUT THE POSSIBLE IMMUNOMODULATORY EFFECTS OF DAPTOMYCIN REMAIN UNKNOWN \\ IN THE PRESENCE OF CALCIUM, DAPTOMYCIN INTERACTS WITH PHOSPHATIDYLCHOLINE, THE MAJOR COMPONENT OF LIPID MEMBRANES IN EUKARYOTIC CELLS}

Cell membrane lipids in eukaryotes consist mainly of glycerophospholipids (GPLs), which are the major structural lipids in cellular membranes $(36,37)$. Although the major conformational change of daptomycin is dependent on interaction with the bacterial acidic phospholipid, phosphatidyl glycerol, in the presence of calcium daptomycin may directly interact with PC, which is the main bilayer-forming lipid in eukaryotic cells including immune cells $(22,25,30)$. However, no studies have investigated the degree of interaction of daptomycin with lipid membranes of immune cells and further studies need to elucidate this possible interaction based on the known immunomodulatory activity of other lipopeptides. 


\section{LIPOPEPTIDES ARE KNOWN ADJUVANTS THAT MAY ENHANCE IMMUNE RESPONSES}

Adjuvants are substances that enhance the immune response in a variety of ways including activation of pattern recognition receptors (PRRs) on antigen presenting cells (APCs), which may result in the upregulation of proteins, such as co-stimulatory molecules and MHC class I and II (38-42). Most adjuvants are not physically associated with antigens and APCs could be activated by the adjuvant without taking up the antigen. Lipid-based adjuvants composed of lipopeptides, phosphatidylethanolamine (PE), PC, liposomes, lipid A $(41,42)$, muramyl dipeptide derivatives (3840,42 ) have previously been shown to exert immunopotentiating effects and increase immune responses in vaccines often through Fc receptor-mediated uptake and $\mathrm{MHC}$ class II presentation of antigens (42-47).

\section{MOST LIPOPEPTIDES INTERACT WITH TOLL-LIKE RECEPTORS}

Lipopeptide adjuvants may form heterodimers with PRRs like Toll-like receptors (TLRs) that are present on APCs including macrophages and dendritic cells (9-11). Recognition by TLRs leads to activation of innate immunity through upregulation of costimulatory molecules and induction of inflammatory cytokines. The discovery of TLRs and their role in lipopeptide recognition contributed significantly to our understanding of how lipopeptides may interact with the immune system (48). Among several hypotheses, including prevention of enzymatic peptide degradation, it has been suggested that the lipid moiety of lipopeptides may be able to incorporate into cell membranes and deliver peptide epitopes into the APCs $(48,49)$. Several lipopeptides impart this self-adjuvanting activity by signaling via Toll-like receptor 2 (TLR2).

\section{THE STRUCTURE OF LIPOPEPTIDES DETERMINES THEIR IMMUNOPOTENTIATING EFFECTS}

Lipopeptides consist of short structures of amino acids linked to fatty acids via ester or amide bonds and the acyl chains are often heterogeneous in terms of their length and degree of saturation. Recent understanding of how the lipid component of lipopeptides confers their activity as adjuvants could form the basis for vaccine development against numerous diseases. Synthetic lipopeptides have been used to determine the contribution of the lipid portion of lipopeptide to TLR2 specific recognition $(9,50)$. Stereochemical properties of the lipid moiety were found to influence aggregation behavior of the TLRs $(51,52)$. The activity of lipopeptides is not only influenced by the number and type of fatty acids present (9) but also on the position of the lipids (53). Lipopeptides may form heterodimers with TLRs that are stabilized by hydrogen bonding and hydrophobic interactions and may promote signaling (54). However, although daptomycin is a lipopeptide that has acyl groups and lipid moiety that could theoretically interact with PRRs like TLRs, this remains to be shown experimentally and the possible immunomodulatory effects of daptomycin have been minimally studied.

\section{THE INTERPLAY BETWEEN DAPTOMYCIN AND IMMUNITY ANTIBIOTICS MAY HAVE IMMUNOMODULATORY EFFECTS}

In addition to their antimicrobial activity, selected classes of antibiotics, like the macrolides, fluoroquinolones, oxazolidinones, and fosfomycin are increasingly recognized to exert immunomodulatory effects (5-8). Those antibiotics show large volumes of distribution, are able to modulate cytokines, may accumulate intracellularly in human blood and body cells to a varying extent, potentially allowing them to interact with DNA and affecting mRNA and protein synthesis (5-8). These immunomodulatory effects of antimicrobials further emphasize the need to elucidate the interplay between antibiotics and immunity, which may set the basis for extended uses of certain antimicrobials especially in the era of increased antimicrobial resistance. However, the possible immunomodulatory effects of daptomycin remain unclear.

\section{DAPTOMYCIN MAY PENETRATE INTO IMMUNE CELLS LIKE NEUTROPHILS AND MACROPHAGES}

Antibiotics may interact with bacteria intracellularly in phagocytes $(55,56)$. Daptomycin may penetrate into human neutrophils and thus may be effective in killing intracellular bacteria (57). In one study, daptomycin had a $60 \%$ penetration to neutrophils (57). In another study, daptomycin had potent intracellular antibacterial effects against intracellular $S$. aureus in human monocyte-derived macrophages (58). Two studies have demonstrated that intracellular daptomycin activity in macrophages depends on the concentration of the extracellular antibiotic and the duration of the exposure to that concentration $(55,58)$. Thus, daptomycin may penetrate into immune cells but the significance of this penetration with regards to immunomodulation remains to be determined.

\section{EFFECTS OF DAPTOMYCIN ON CYTOKINE PRODUCTION AND INNATE IMMUNITY}

Antibiotics may affect the overall balance of pro- and antiinflammatory cytokines. The ability of daptomycin to affect proinflammatory cytokines was determined in one study by utilizing an established whole blood in vitro model (59). Thallinger et al. found that the addition of daptomycin at a therapeutically relevant concentration of $40 \mu \mathrm{g} / \mathrm{ml}$ in an experimental model of human endotoxemia had no effect on cytokines such as interleukin- $1 \beta$ (IL$1 \beta)$, IL-6, and tumor necrosis factor alpha (TNF- $\alpha$ ), neither on the mRNA nor on the protein levels (59). In the experimental in vitro study of Pichereau et al. on peripheral blood mononuclear cells, many different antibiotics including daptomycin, tended to reduce production of cytokines after toxin exposure (60). In the in vitro study of English et al., exposure of $S$. aureus isolates to daptomycin alone or in combination with vancomycin or oxacillin reduced macrophage inflammatory responses such as tumor necrosis factor secretion and accumulation of inducible nitric oxide synthase protein (compared with vancomycin or oxacillin alone) (61). The lack of any significant immunomodulatory effect of daptomycin observed in these preliminary studies may be explained by its very low volume of distribution. Although daptomycin has been shown to penetrate into immune cells (55-58), it remains to be determined whether the penetration of daptomycin into human cells is clinically significant because of the very hydrophilic, watersoluble core of this antibiotic. However, the uptake of daptomycin into mononuclear cells, which, beside the neutrophils, are mainly responsible for cytokine production and release, occurs predominantly via phagocytosis and pinocytosis. The penetration of daptomycin into the cell's cytosol and nucleus is required for daptomycin 
to exert immunomodulatory effects on the human DNA $(57,58)$. Thus, daptomycin may be less likely to affect levels of cytokines probably due to high affinity of daptomycin to bacterial cytoplasmic membrane and its low potential to penetrate into human cells (59). Further studies are needed to determine the effects of daptomycin on cytokines. In one animal study in Balb/c mice, daptomycin did not affect humoral and cell-mediated immune responses such as polymorphonuclear phagocytic activity but the concentrations of daptomycin used were not representative for the concentrations used in humans after administration of standard dosages (62). Thus, it is important that in all the in vitro and in vivo studies testing immunomodulatory effects of antimicrobial agents, the concentrations of daptomycin should be representative for the concentrations used in humans after administration of standard dosages. In addition, the use of whole blood instead of peripheral blood mononuclear cells, as frequently done in many in vitro studies may reflect a more realistic clinical situation than the use of isolated, selected immunocompetent blood cells.

\section{DAPTOMYCIN MAY HAVE SYNERGISTIC IMMUNOMODULATORY EFFECTS IN COMBINATION WITH OTHER IMMUNOMODULATORS LIKE VITAMIN E}

Vitamin E intake is associated with increased antimicrobial resistance (63-65). Current data revealed immunomodulatory properties of vitamin $\mathrm{E}$ also in human peripheral mononuclear cells altering cytokine production [interleukin (IL)-2, IL-8, and IL-17] in part by stimulating production of cyclic adenosine monophosphate (cAMP) (66). In an animal model, administration of the immune enhancer vitamin E before infecting 100 wounds by MRSA improved later the efficacy of daptomycin (67). Additionally, Pierpaoli et al. found that immune modulation was related to the antimicrobial effect of vitamin $\mathrm{E}$ with or without daptomycin (65). Gr-1+ cells and CD49b + cells significantly increased in mice treated with vitamin $\mathrm{E}$ while daptomycin alone did not affect any of the leukocyte populations compared to control infected animals (65). Vitamin E plus daptomycin significantly increased CD49b + cells compared with control infected animals or mice treated with vitamin $\mathrm{E}$ alone (65). Thus in animals treated with vitamin $\mathrm{E}$ with or without daptomycin, immunological changes such as modulation of natural killer (NK) cell activity and changes in leukocytes were associated with significant antibacterial activity (65). Further studies are needed to determine the possible immunomodulatory effects of daptomycin in combination with vitamins in humans (65).

\section{DAPTOMYCIN AND NK CELL ACTIVITY}

In one study, it was shown that administration of vitamin E plus daptomycin was associated with modulation of NK cell activity compared to controls (65). The groups given vitamin E plus daptomycin had significant increase in NK activity and cytotoxicity compared to vitamin E only or untreated animals suggesting an association of the antimicrobial effects with the immune modulation induced by the combination of daptomycin with vitamin $\mathrm{E}$ (67). Daptomycin alone did not significantly enhance NK activity compared with untreated infected mice. NK cells may bridge innate and adaptive immune responses and some of them respond to a variety of lipid antigens (68). Further studies are needed to

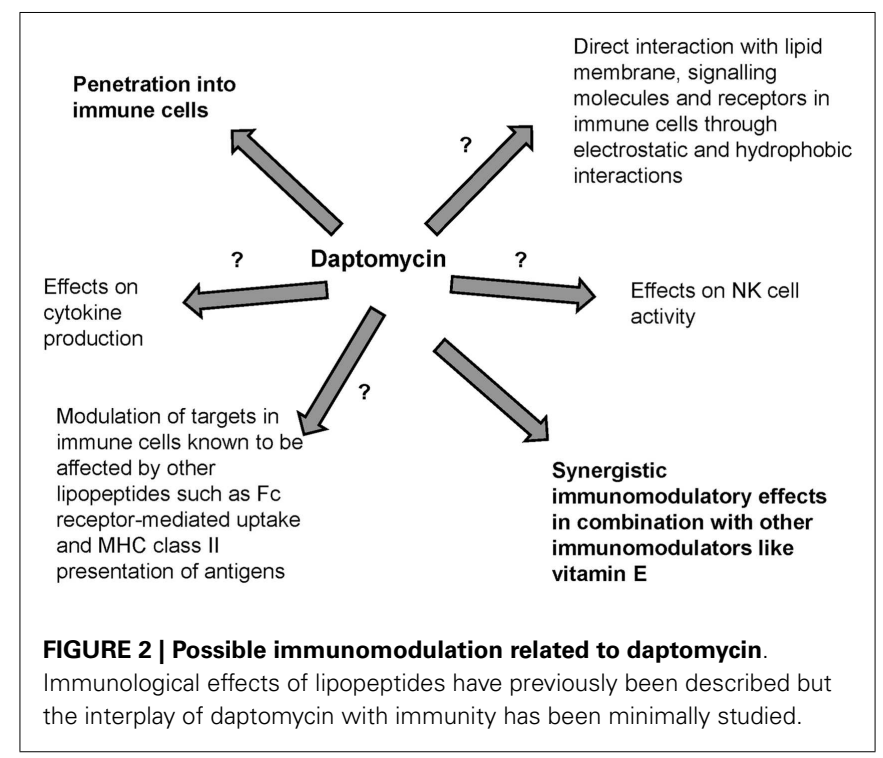

understand the possible interaction between the lipid moiety of lipopeptide antibiotics and NK cells (65).

\section{CONCLUSION}

Antibiotics may have bactericidal effects but may also cause immunomodulation. Lipopeptides are known adjuvants and immunomodulators that interact with PRRs such as TLRs in APCs. Daptomycin is a novel lipopeptide antibiotic that is largely watersoluble with a low volume of distribution but its lipid moiety and unique structure in the presence of divalent ions contribute to direct interaction with lipid membrane phospholipids. Although daptomycin preferentially interacts with acidic phospholipids that are present in the lipid membrane of gram-positive pathogens, it may also directly interact with human surfactant and PC, the major component of lipid membranes in immune cells. Daptomycin may also penetrate immune cells including neutrophils and macrophages. However, the possible immunomodulatory effects of daptomycin remain unknown (Figure 2). Preliminary studies suggest that daptomycin may have minimal effects on cytokine production and may have synergistic immunomodulatory effects (such as effects on NK cell activity) in combination with other immunomodulators. Understanding whether daptomycin may be an immunomodulatory agent is important to optimize the clinical use of this agent, especially in the era of increased antimicrobial resistance. Further studies are needed to investigate the interplay between daptomycin and immunity.

\section{REFERENCES}

1. Walsh CT, Fischbach MA. Natural products version 2.0: connecting genes to molecules. J Am Chem Soc (2010) 132(8):2469-93. doi:10.1021/ja909118a

2. Enoch DA, Bygott JM, Daly ML, Karas JA. Daptomycin. J Infect (2007) 55(3):205-13. doi:10.1016/j.jinf.2007.05.180

3. Tally FP, Zeckel M, Wasilewski MM, Carini C, Berman CL, Drusano GL, et al. Daptomycin: a novel agent for gram-positive infections. Expert Opin Investig Drugs (1999) 8(8):1223-38. doi:10.1517/13543784.8.8.1223

4. Sauermann R, Rothenburger M, Graninger W, Joukhadar C. Daptomycin: a review 4 years after first approval. Pharmacology (2008) 81(2):79-91. doi:10. $1159 / 000109868$ 
5. Sauermann R, Marsik C, Steiner I, Seir K, Cvitko T, Zeitlinger M, et al. Immunomodulatory effects of fosfomycin in experimental human endotoxemia. Antimicrob Agents Chemother (2007) 51(5):1879-81. doi:10.1128/AAC. 00914-06

6. Zeitlinger M, Marsik C, Steiner I, Sauermann R, Seir K, Jilma B, et al. Immunomodulatory effects of fosfomycin in an endotoxin model in human blood. J Antimicrob Chemother (2007) 59(2):219-23. doi:10.1093/jac/dkl464

7. Dalhoff A, Shalit I. Immunomodulatory effects of quinolones. Lancet Infect Dis (2003) 3(6):359-71. doi:10.1016/S1473-3099(03)00658-3

8. Dalhoff A. Immunomodulatory activities of fluoroquinolones. Infection (2005) 33(Suppl 2):55-70. doi:10.1007/s15010-005-8209-8

9. Spohn R, Buwitt-Beckmann U, Brock R, Jung G, Ulmer AJ, Wiesmuller KH. Synthetic lipopeptide adjuvants and Toll-like receptor 2 - structure-activity relationships. Vaccine (2004) 22(19):2494-9. doi:10.1016/j.vaccine.2003.11.074

10. Zom GG, Khan S, Filippov DV, Ossendorp F. TLR ligand-peptide conjugate vaccines: toward clinical application. Adv Immunol (2012) 114:177-201. doi:10.1016/B978-0-12-396548-6.00007-X

11. Farhat K, Riekenberg S, Heine H, Debarry J, Lang R, Mages J, et al. Heterodimerization of TLR2 with TLR1 or TLR6 expands the ligand spectrum but does not lead to differential signaling. J Leukoc Biol (2008) 83(3):692-701. doi:10.1189/jlb.0807586

12. Debono M, Barnhart M, Carrell CB, Hoffmann JA, Occolowitz JL, Abbott BJ, et al. A21978C, a complex of new acidic peptide antibiotics: isolation, chemistry, and mass spectral structure elucidation. J Antibiot (Tokyo) (1987) 40(6):761-77. doi:10.7164/antibiotics.40.761

13. Miao V, Coeffet-Legal MF, Brian P, Brost R, Penn J, Whiting A, et al. Daptomycin biosynthesis in Streptomyces roseosporus: cloning and analysis of the gene cluster and revision of peptide stereochemistry. Microbiology (2005) 151(Pt 5):1507-23. doi:10.1099/mic.0.27757-0

14. Robbel L, Marahiel MA. Daptomycin, a bacterial lipopeptide synthesized by a nonribosomal machinery. J Biol Chem (2010) 285(36):27501-8. doi:10.1074/ jbc.R110.128181

15. Debono M, Abbott BJ, Molloy RM, Fukuda DS, Hunt AH, Daupert VM, et al. Enzymatic and chemical modifications of lipopeptide antibiotic A21978C: the synthesis and evaluation of daptomycin (LY146032). J Antibiot (Tokyo) (1988) 41(8):1093-105. doi:10.7164/antibiotics.41.1093

16. Yazawa M, Yagi K. The amino acid sequence of the calmodulin obtained from sea anemone (metridium senile) muscle. Biochem Biophys Res Commun (1980) 96(1):377-81. doi:10.1016/0006-291X(80)91225-5

17. Hojati Z, Milne C, Harvey B, Gordon L, Borg M, Flett F, et al. Structure, biosynthetic origin, and engineered biosynthesis of calcium-dependent antibiotics from Streptomyces coelicolor. Chem Biol (2002) 9(11):1175-87. doi:10.1016/ S1074-5521(02)00252-1

18. Counter FT, Allen NE, Fukuda DS, Hobbs JN, Ott J, Ensminger PW, et al. A54145 a new lipopeptide antibiotic complex: microbiological evaluation. J Antibiot (Tokyo) (1990) 43(6):616-22. doi:10.7164/antibiotics.43.616

19. Lakey JH, Lea EJ, Rudd BA, Wright HM, Hopwood DA. A new channel-forming antibiotic from Streptomyces coelicolor A3(2) which requires calcium for its activity. J Gen Microbiol (1983) 129(12):3565-73.

20. Marahiel MA, Essen LO. Chapter 13. Nonribosomal peptide synthetases mechanistic and structural aspects of essential domains. Methods Enzymol (2009) 458:337-51. doi:10.1016/S0076-6879(09)04813-7

21. Marahiel MA. Working outside the protein-synthesis rules: insights into nonribosomal peptide synthesis. J Pept Sci (2009) 15(12):799-807. doi:10.1002/psc. 1183

22. Silverman JA, Perlmutter NG, Shapiro HM. Correlation of daptomycin bactericidal activity and membrane depolarization in Staphylococcus aureus. Antimicrob Agents Chemother (2003) 47(8):2538-44. doi:10.1128/AAC.47.8.25382544.2003

23. Baltz RH, Miao V, Wrigley SK. Natural products to drugs: daptomycin and related lipopeptide antibiotics. Nat Prod Rep (2005) 22(6):717-41. doi:10.1039/ b416648p

24. Ho SW, Jung D, Calhoun JR, Lear JD, Okon M, Scott WR, et al. Effect of divalent cations on the structure of the antibiotic daptomycin. Eur Biophys J (2008) 37(4):421-33. doi:10.1007/s00249-007-0227-2

25. Jung D, Rozek A, Okon M, Hancock RE. Structural transitions as determinants of the action of the calcium-dependent antibiotic daptomycin. Chem Biol (2004) 11(7):949-57. doi:10.1016/j.chembiol.2004.04.020
26. Scott WR, Baek SB, Jung D, Hancock RE, Straus SK. NMR structural studies of the antibiotic lipopeptide daptomycin in DHPC micelles. Biochim Biophys Acta (2007) 1768(12):3116-26. doi:10.1016/j.bbamem.2007.08.034

27. Straus SK, Hancock RE. Mode of action of the new antibiotic for grampositive pathogens daptomycin: comparison with cationic antimicrobial peptides and lipopeptides. Biochim Biophys Acta (2006) 1758(9):1215-23. doi:10. 1016/j.bbamem.2006.02.009

28. Ball LJ, Goult CM, Donarski JA, Micklefield J, Ramesh V. NMR structure determination and calcium binding effects of lipopeptide antibiotic daptomycin. Org Biomol Chem (2004) 2(13):1872-8. doi:10.1039/b402722a

29. Rozek A, Friedrich CL, Hancock RE. Structure of the bovine antimicrobial peptide indolicidin bound to dodecylphosphocholine and sodium dodecyl sulfate micelles. Biochemistry (2000) 39(51):15765-74. doi:10.1021/bi000714m

30. Lakey JH, Ptak M. Fluorescence indicates a calcium-dependent interaction between the lipopeptide antibiotic LY146032 and phospholipid membranes. Biochemistry (1988) 27(13):4639-45. doi:10.1021/bi00413a009

31. Lakey JH, Maget-Dana R, Ptak M. The lipopeptide antibiotic A21978C has a specific interaction with DMPC only in the presence of calcium ions. Biochim Biophys Acta (1989) 985(1):60-6. doi:10.1016/0005-2736(89)90104-1

32. Goerke J. Pulmonary surfactant: functions and molecular composition. Biochim Biophys Acta (1998) 1408(2-3):79-89. doi:10.1016/S0925-4439(98) 00060-X

33. White DC, Frerman FE. Extraction, characterization, and cellular localization of the lipids of Staphylococcus aureus. J Bacteriol (1967) 94(6): 1854-67.

34. Maget-Dana R, Lakey JH, Ptak M. A comparative monomolecular film study of antibiotic A21978C homologues of various lipid chain length. Biochim Biophys Acta (1988) 962(2):201-7. doi:10.1016/0005-2760(88)90160-9

35. Jung D, Powers JP, Straus SK, Hancock RE. Lipid-specific binding of the calcium-dependent antibiotic daptomycin leads to changes in lipid polymorphism of model membranes. Chem Phys Lipids (2008) 154(2):120-8. doi:10.1016/j.chemphyslip.2008.04.004

36. Cullis PR, de KB. Lipid polymorphism and the functional roles of lipids in biological membranes. Biochim Biophys Acta (1979) 559(4):399-420. doi:10.1016/ 0304-4157(79)90012-1

37. Sonnino S, Prinetti A. Membrane domains and the "lipid raft" concept. Curr Med Chem (2013) 20(1):4-21. doi:10.2174/0929867311320010003

38. Morein B. The iscom: an immunostimulating system. Immunol Lett (1990) 25(1-3):281-3. doi:10.1016/0165-2478(90)90128-D

39. Allison AG, Gregoriadis G. Liposomes as immunological adjuvants. Nature (1974) 252(5480):252. doi:10.1038/252252a0

40. Garcon NM, Six HR. Universal vaccine carrier. Liposomes that provide Tdependent help to weak antigens. J Immunol (1991) 146(11):3697-702.

41. Ribi E, Milner KC, Granger DL, Kelly MT, Yamamoto K, Brehmer W, et al. Immunotherapy with nonviable microbial components. Ann N Y Acad Sci (1976) 277:228-38. doi:10.1111/j.1749-6632.1976.tb41700.x

42. Gluck R, Mischler R, Brantschen S, Just M, Althaus B, Cryz SJ Jr. Immunopotentiating reconstituted influenza virus virosome vaccine delivery system for immunization against hepatitis A. J Clin Invest (1992) 90(6):2491-5. doi:10. 1172/JCI116141

43. Neurath AR, Kent SB, Strick N. Antibodies to hepatitis B surface antigen (HBsAg) elicited by immunization with a synthetic peptide covalently linked to liposomes. J Gen Virol (1984) 65(Pt 5):1009-14. doi:10.1099/0022-1317-655- 1009

44. Lifshitz R, Gitler C, Mozes E. Liposomes as immunological adjuvants in eliciting antibodies specific to the synthetic polypeptide poly(LTyr, LGlu)poly(DLAla) - (LLys) with high frequency of site-associated idiotypic determinants. Eur J Immunol (1981) 11(5):398-404. doi:10.1002/eji.1830110510

45. Engers HD, Godal T. Malaria vaccine development: current status. Parasitol Today (1998) 14(2):56-64. doi:10.1016/S0169-4758(97)01184-8

46. Hopp TP. Immunogenicity of a synthetic HBsAg peptide: enhancement by conjugation to a fatty acid carrier. Mol Immunol (1984) 21(1):13-6. doi:10.1016/ 0161-5890(84)90084- 1

47. Yasuda T, Dancey GF, Kinsky SC. Immunogenicity of liposomal model membranes in mice: dependence on phospholipid composition. Proc Natl Acad Sci US A (1977) 74(3):1234-6. doi:10.1073/pnas.74.3.1234

48. Loing E, Andrieu M, Thiam K, Schorner D, Wiesmuller KH, Hosmalin A, et al. Extension of HLA-A ${ }^{*} 0201-$ restricted minimal epitope by $\mathrm{N}$ 
epsilon-palmitoyl-lysine increases the life span of functional presentation to cytotoxic T cells. J Immunol (2000) 164(2):900-7.

49. Thiam K, Loing E, Verwaerde C, Auriault C, Gras-Masse H. IFN-gamma-derived lipopeptides: influence of lipid modification on the conformation and the ability to induce MHC class II expression on murine and human cells. J Med Chem (1999) 42(18):3732-6. doi:10.1021/jm991025f

50. Buwitt-Beckmann U, Heine H, Wiesmuller KH, Jung G, Brock R, Ulmer AJ. Lipopeptide structure determines TLR2 dependent cell activation level. FEBS J (2005) 272(24):6354-64. doi:10.1111/j.1742-4658.2005.05029.x

51. Reichel F, Roelofsen AM, Geurts HP, van Der Gaast SJ, Feiters MC, Boons GJ. Synthesis and supramolecular characterization of a novel class of glycopyranosylcontaining amphiphiles. J Org Chem (2000) 65(11):3357-66. doi:10.1021/ jo991685s

52. Khan S, Weterings JJ, Britten CM, de Jong AR, Graafland D, Melief CJ, et al. Chirality of TLR-2 ligand Pam3CysSK4 in fully synthetic peptide conjugates critically influences the induction of specific CD8+ T-cells. Mol Immunol (2009) 46(6):1084-91. doi:10.1016/j.molimm.2008.10.006

53. Zeng W, Ghosh S, Lau YF, Brown LE, Jackson DC. Highly immunogenic and totally synthetic lipopeptides as self-adjuvanting immunocontraceptive vaccines. J Immunol (2002) 169(9):4905-12.

54. Jin MS, Kim SE, Heo JY, Lee ME, Kim HM, Paik SG, et al. Crystal structure of the TLR1-TLR2 heterodimer induced by binding of a tri-acylated lipopeptide. Cell (2007) 130(6):1071-82. doi:10.1016/j.cell.2007.09.008

55. Barcia-Macay M, Seral C, Mingeot-Leclercq MP, Tulkens PM, Van BF. Pharmacodynamic evaluation of the intracellular activities of antibiotics against Staphylococcus aureus in a model of THP-1 macrophages. Antimicrob Agents Chemother (2006) 50(3):841-51. doi:10.1128/AAC.50.3.841-851.2006

56. Carryn S, Chanteux H, Seral C, Mingeot-Leclercq MP, Van BF, Tulkens PM. Intracellular pharmacodynamics of antibiotics. Infect Dis Clin North Am (2003) 17(3):615-34. doi:10.1016/S0891-5520(03)00066-7

57. Van der Auwera P, Matsumoto T, Husson M. Intraphagocytic penetration of antibiotics. J Antimicrob Chemother (1988) 22(2):185-92. doi:10.1093/jac/ 22.2.185

58. Baltch AL, Ritz WJ, Bopp LH, Michelsen PB, Smith RP. Antimicrobial activities of daptomycin, vancomycin, and oxacillin in human monocytes and of daptomycin in combination with gentamicin and/or rifampin in human monocytes and in broth against Staphylococcus aureus. Antimicrob Agents Chemother (2007) 51(4):1559-62. doi:10.1128/AAC.00973-06

59. Thallinger C, Rothenburger M, Marsik C, Wuenscher S, Popovic M, Endler G, et al. Daptomycin does not exert immunomodulatory effects in an experimental endotoxin model of human whole blood. Pharmacology (2008) 81(1):57-62. doi:10.1159/000108106

60. Pichereau S, Moran JJ, Hayney MS, Shukla SK, Sakoulas G, Rose WE. Concentration-dependent effects of antimicrobials on Staphylococcus aureus toxin-mediated cytokine production from peripheral blood mononuclear cells. J Antimicrob Chemother (2012) 67(1):123-9. doi:10.1093/jac/dkr417
61. English BK, Maryniw EM, Talati AJ, Meals EA. Diminished macrophage inflammatory response to Staphylococcus aureus isolates exposed to daptomycin versus vancomycin or oxacillin. Antimicrob Agents Chemother (2006) 50(6):2225-7. doi:10.1128/AAC.01559-05

62. Tawfik AF. Effects of vancomycin, teicoplanin, daptomycin and coumermycin on normal immune capabilities. J Chemother (1991) 3(4):226-31.

63. Wu D, Meydani SN. Age-associated changes in immune and inflammatory responses: impact of vitamin E intervention. J Leukoc Biol (2008) 84(4):900-14. doi:10.1189/jlb.0108023

64. Tengerdy RP. The role of vitamin $\mathrm{E}$ in immune response and disease resistance. Ann N Y Acad Sci (1990) 587:24-33.

65. Pierpaoli E, Cirioni O, Barucca A, Orlando F, Silvestri C, Giacometti A, et al. Vitamin E supplementation in old mice induces antimicrobial activity and improves the efficacy of daptomycin in an animal model of wounds infected with methicillin-resistant Staphylococcus aureus. JAntimicrob Chemother (2011) 66(9):2184-5. doi:10.1093/jac/dkr254

66. Salinthone S, Kerns AR, Tsang V, Carr DW. $\alpha$-Tocopherol (vitamin E) stimulates cyclic AMP production in human peripheral mononuclear cells and alters immune function. Mol Immunol (2013) 53(3):173-8. doi:10.1016/j.molimm. 2012.08.005

67. Provinciali M, Cirioni O, Orlando F, Pierpaoli E, Barucca A, Silvestri C, et al. Vitamin $\mathrm{E}$ improves the in vivo efficacy of tigecycline and daptomycin in an animal model of wounds infected with methicillin-resistant Staphylococcus aureus. J Med Microbiol (2011) 60(Pt 12):1806-12. doi:10.1099/jmm.0. 032516-0

68. Mallevaey T, Selvanantham T. Strategy of lipid recognition by invariant natural killer T cells: 'one for all and all for one'. Immunology (2012) 136(3):273-82. doi:10.1111/j.1365-2567.2012.03580.x

Conflict of Interest Statement: The author declares that the research was conducted in the absence of any commercial or financial relationships that could be construed as a potential conflict of interest.

Received: 11 December 2013; accepted: 29 January 2014; published online: 12 February 2014.

Citation: Kelesidis T (2014) The interplay between daptomycin and the immune system. Front. Immunol. 5:52. doi: 10.3389/fimmu.2014.00052

This article was submitted to Microbial Immunology, a section of the journal Frontiers in Immunology.

Copyright $\odot 2014$ Kelesidis. This is an open-access article distributed under the terms of the Creative Commons Attribution License (CC BY). The use, distribution or reproduction in other forums is permitted, provided the original author $(s)$ or licensor are credited and that the original publication in this journal is cited, in accordance with accepted academic practice. No use, distribution or reproduction is permitted which does not comply with these terms. 